\title{
Colorectal Adenocarcinoma and Inflammatory Bowel Disease: An Update and Review
}

\section{Michael Laffin ${ }^{1}$ and Shahzeer Karmali ${ }^{*}$}

${ }^{1}$ Department of Surgery, University of Alberta, Edmonton, Alberta, Canada

${ }^{2}$ Center for the Advancement of Minimally Invasive Surgery (CAMIS), Edmonton, Alberta, Canada

\begin{abstract}
Inflammatory bowel disease and its two prototypic illnesses: Crohn's disease and ulcerative colitis have long been thought to confer an increased risk of colorectal cancer, although the magnitude of this effect has been difficult to elucidate. The driving factors behind this relationship include genetics, microbial disturbances, alongside molecular and inflammatory misregulation. The epidemiologic understanding of the inflammatory bowel disease-colorectal cancer relationship has evolved over the last decade. This review will focus on the epidemiology of colorectal cancer in inflammatory bowel disease, and detail the elements driving disease development. Patient risk factors, many that increase the intensity or duration of inflammation, will be detailed. Finally, a practical approach to the tools that clinicians have at their disposal in preventing this disease, including the effect of different medications and timing of colonoscopy will be presented.
\end{abstract}

Keywords: Inflammatory bowel disease; Colorectal cancer; Epidemiology

\section{Introduction}

Inflammatory bowel disease (IBD) encompasses two illnesses Crohn's disease (CD) and ulcerative colitis (UC) - that are characterized by chronic intestinal inflammation. The disease progression of IBD is heterogeneous, as is the response of individual patients to different treatments. Typically IBD and the resultant inflammation cause a combination of abdominal pain, diarrhea, intestinal bleeding, weight loss, malabsorption and nutritional deficiencies. The onset of IBD is greatest in early adulthood, with peak incidence among those aged 18 to 35 [1]. Diagnosis at this stage of life has a significant impact on employment and psychosocial functioning of the affected. Up to $25 \%$ of cases of IBD are diagnosed during childhood [2]. There are approximately 1.4 million Americans living with IBD, with a prevalence of 201 and 238 per 100,000 for CD and UC respectively [3]. Medical costs for each IBD patient in the United States is estimated to be over $\$ 18000$ per year [4].

There is a concern in patients with IBD that their disease can predispose them to an increased risk of neoplasia of the bowel. This increased risk was first noted by Crohn and Rosberg in 1925 [5] and further explored in the 1930s in patients undergoing an at-the-time popular procedure for IBD, bypass of the diseased segment. Those who had a section of diseased small bowel left in situ seemed to develop carcinoma at an abnormally high rate [6]. The increase in risk was thought to be secondary to long-standing chronic inflammation [7]. This literature review, constructed after a review of PubMed and Medline databases using the search terms 'Crohn's Disease', 'Ulcerative Colits', 'inflammatory bowel disease' and 'colorectal cancer' will provide a narrative overview of the epidemiology of cancer in IBD, the molecular basis of these changes, how different IBD phenotypes affect cancer, and how the tools modern clinicians use to treat IBD affect the progression of this disease.

\section{Epidemiology}

CRC is a major cause of mortality throughout the world [8], is the third most common cancer worldwide and is the fourth most common cause of death among cancers [9]. In IBD the outcomes may be worse than in the general population, with a 2 fold increase in mortality associated with IBD-associated CRC compared to sporadic cancers [10]. Although an increased CRC risk associated with IBD has been suspected, the exact effect, and its magnitude, has been difficult to determine. This difficulty stems from a number of factors, one of which is the scope of patient recruitment. Tertiary referral based studies likely overestimate the risk by including mainly subjects with severe disease, and population-based studies, are likely to underestimate the risk by including patients with mild disease. Another factor that limits the generalizability of epidemiological results is the geographic gradient in CRC and IBD-associated CRC [11]. Studies from both European and Asian centres have shown differences in IBD-associated CRC within each respective region [12-15]. Regardless of these issues, there are important lessons to be learned from the data.

First, UC seems to be associated with a greater risk of IBDassociated CRC than $\mathrm{CD}$, and in fact, the role of $\mathrm{CD}$ in the development of CRC is equivocal. Initial studies involving UC-associated CRC were hospital based, and neglected the general IBD population [16]. A widely-cited 2001 meta-analysis of these studies indicated that incidence in UC patients was 3/1000 person-years disease duration (PYD) [16]. In this analysis, there was a $2 \%$ probability of suffering from a CRC in UC patients after 10 years of disease, $8 \%$ by 20 years and $18 \%$ by 30 years. However, care of UC patients has changed a great deal in the intervening years, and along with changes in the methodology of patient recruitment, this has led to a change in reported prevalence. From 1979 to 1988 the relative risk of CRC in UC was noted to be 1.34 with that decreasing to 0.57 between 1999 and 2008 [17], and similarly incidence rates have decreased from 4.29/1000 PYD in the 1950s to $1.09 / 1000$ in the first part of the 2000s [18]. Moreover, incidence rates in the first, second, and third decades of disease have decreased to 1.01/1000, 3.75/1000 and 5.85/1000 PYD respectively [18].

Though the link between CRC development and UC seems to

*Corresponding author: Karmali S, Department of Surgery, University of Alberta, Room 405, CSC 10240 Kingsway Avenue, Edmonton, Alberta, Canada, Tel: 780735-6650; Fax: 780-735-6652; E-mail: shahzeer@ualberta.ca

Received July 22, 2015; Accepted September 12, 2015; Published September 19, 2015

Citation: Laffin M, Karmali S (2015) Colorectal Adenocarcinoma and Inflammatory Bowel Disease: An Update and Review. Surgery Curr Res 5: 249. doi:10.4172/21611076.1000249

Copyright: $\odot 2015$ Laffin M, et al. This is an open-access article distributed under the terms of the Creative Commons Attribution License, which permits unrestricted use, distribution, and reproduction in any medium, provided the original author and source are credited. 
be weakening, the association between $\mathrm{CD}$ and $\mathrm{CRC}$ has never been especially strong. This may be due to the heterogeneity of disease phenotype, and specifically the degree of colonic involvement. That is, in those $\mathrm{CD}$ subjects with extensive colitis, there appears to be somewhat of an increased risk, while those with disease limited to the small bowel appear to be at a baseline risk [19-21]. When all phenotypes of Crohn's disease are included, some studies place the relative risk of CRC between 2 and 3 [22-24], whereas others do not demonstrate any increased risk $[17,25,26]$.

\section{The development of CRC and the impact of IBD}

There are a variety of epithelial-derived neoplastic growths that occur in the colon, ranging from benign tumors to invasive cancers. Over $90 \%$ of CRC are carcinomas, and $95 \%$ of those cancers are adenocarcinomas [27]. It is hypothesized that adenocarcinomas arise from adenomas, which arise from normal epithelium [28]. A large body of work has focused on the molecular and genetic basis of CRC, with genomic instability, the mutational inactivation of tumor-suppressor genes, and the activation of oncogene pathways taking center stage [29]. A number of pathways have garnered special interest, and seem to play a prominent role in IBD-associated CRC.

One such pathway involves an important class of molecules, toll-like receptors (TLRs). TLRs recognize molecules unique to microbes, and constitute the primary strategy for self versus non-self-discrimination. TLR-4 variants are associated with Crohn's disease [30] and with the adaptor protein- myeloid differentiation factor 88 (MYD88), a common signal transduction molecule for many TLRs-. MYD88knockout mice were shown to be highly susceptible to the development adenocarcinoma of the colon in some experiments [31] but decrease intestinal tumorgenesis in other models $[32,33]$. The role of TLR and carcinogenesis is complex, and future work may focus on downstream molecules (i.e. MYD88) to pinpoint their effect.

Cytokines encompass a wide-body of signaling proteins and include a number of pro-inflammatory markers, such as tumor necrosis factor- $\alpha$ (TNF- $\alpha$ ), interleukin- 6 and interleukin-21. TNFA is highly expressed in the colon of IBD patients [34], anti-TNF antibodies are commonly used in the treatment of IBD. Blocking downstream TNFA products in a mouse-model has demonstrated a reduction in tumor formation [35]. Interleukin-6 is also associated with IBD and IBDassociated CRC [36]. Interleukin-21 has a broad set of target cells, including T cells, B cells, natural killer cells and dendritic cells [37]. In interlukin-21 knockout mice tumorgenesis has shown to be decreased, along with a decrease in colitis [38]. The inflammatory effects of these three cytokines likely play a role in IBD-associated CRC, though other mechanisms of tumorigenesis are a possibility.

A number of transcription factors have been implicated in IBDassociated CRC [39], the two most well understood being NF- $\kappa B$, and STAT3. NF- $\kappa B$, which is hyperactive in IBD, regulates a number of cytokines, and has been seen to regulate proliferation, and survival in tumor cells [40]. By blocking its effect in the intestinal epithelial cells of a mouse model, a dramatic decrease in tumor incidence was noted, despite an increase in inflammation [41]. This suggests that an increase in inflammation may stimulate tumorigenesis but cells first must possess the ability to proliferate in these environments for abnormal cells to take hold. STAT [3], which is activated downstream in a pathway initiated by interleukin-6, is present in the inflammatory environment of tumor cells [42]. It regulates antiapoptotic proteins, and proto-oncogenes [43]. STAT3 expression is greater in UC patients with CRC [44]. Taken together, these molecular changes provide a framework for which IBD-associated CRC can take hold.

\section{Microbes}

The human intestine provides a diverse ecosystem which supports a multitude of microorganisms. It has been estimated that the average human's gut contains approximately $10^{14}$ microorganisms [45]. The majority of these species cannot yet be cultured [45]. There are only a few dominant phyla found in the gut. These include Firmicutes, Bacteroides, Actinobacteria, Proteobacteria, and Fusobacteria. Although these types dominate, there are over 1500 genera and thousands of different species present [45]. IBD patients exhibit a "dysbiosis" in their gut microbiota but whether these changes are causative or associative remains to be shown $[46,47]$. A number of difference have been described in the literature, with studies having found changes in the number of microbes present, alterations in community composition, increased adherence to mucosa, invasiveness or virulence of select species, and alterations in functional and metabolic characteristics $[46,47]$. Germ-free mice, those with no intestinal bacteria, are less likely to develop oncogenetic mutations or tumor formation $[48,49]$.

A number of individual bacterial species have been indicated in the development of IBD-associated CRC. Helicobacter species leads to cancer development in a mouse-model of colitis, while eradication protected the gut from tumor formation [50]. Adherent-invasive Escherichia coli is also associated with invasive carcinoma in the same mouse model [51]. B. fragilis triggers colitis but also seems to contribute to oncogenic signaling via disruption of E-cadherin signaling [52,53]. The question of whether this microbe causes CRC or simply thrives in a niche created by the development of CRC remains to be seen.

\section{Risk Factors}

A number of factors are thought to be associated with an increased risk of IBD-associated CRC. The majority of these can be thought of as those that increase the intensity or duration of inflammation. Classicaly, disease duration has been implicated, and the landmark meta-analysis by Eaden demonstrated appreciable risk occurring at approximately 10 years after disease onset [16]. This wisdom has been called into question recently, as two large studies did not show any trend of increased incidence with increased disease duration $[54,55]$.

An increase in inflammation extension seems to increase the risk of CRC. Regarding UC, proctitis has a low relative risk (1.7) while pancolitis demonstrates a much high relative risk (5.6) [55]. As previously stated CD subjects with colitis appear to incur an increased risk of CRC compared to those with disease limited to the terminal ileum [19-21]. These observations are consistent with the cancer field effect theory, where when a large number of cells are exposed to a potentially carcinogenic insult, in this case inflammation, there is a higher likelihood in developing carcinogenic alterations. There is also evidence that inflammation intensity increase the risk of CRC. C-reactive protein and erythrocyte sedimentation rate are markers of inflammation, and can be taken as surrogate for disease activity [56]. IBD patients with an increase in either of these markers have been shown to be more likely to develop CRC [56]. Histologic inflammation has been shown to be associated with IBD-associated CRC $[57,58]$. In terms of disease flares and increased CRC risk evidence is mixed. Some studies demonstrated an association between increased hospitalizations and increased frequency of IBD exacerbations and increased risk of CRC $[59,60]$. On the other hand, other studies have shown that exacerbations have not increased CRC risk [61].

Factors outside of extent and intensity of inflammation may also 
affect CRC risk. There is equivocal evidence regarding age at diagnosis of IBD, and CRC risk. Initially early diagnosis was associated with increased risk $[16,19]$, while other work has demonstrated the opposite effect, with those who are elderly at diagnosis at higher risk [62,63]. Male gender also increase the risk Primary sclerosing cholangitis confers a 4-fold increase in risk of CRC development in UC patients [17,6466], with the increased risk persisting following liver transplantation $[67,68]$.

Familial clustering in cases of inflammatory bowel disease and Crohn's disease is well recognized. A concordance study focusing on twins in northern Europe was the first large scale study to demonstrate a genetic component 1. A familial predisposition has also been noted in patients with CRC. IBD patients may have up to a 2.5 times risk of developing CRC if they have a family history of CRC, and up to a 9 times higher risk if a first-degree relative has been diagnosed with a CRC before 50 years of age [69].

\section{Prevention of CRC}

While the understanding of the initiating events of IBD-associated CRC will be important in preventing this disease in the future, there are currently a number of clinical treatment options which can alter the disease's course. Of course, total proctocolectomy totally removes the risk of CRC, but less extreme options are often preferable, especially in $\mathrm{CD}$ where complete removal of colonic tissue would not eliminate the $\mathrm{CD}$.

5- aminosalicylic acid (5-ASA) compounds are used to interfere with a number of metabolic and genomic pathways, some of which are implicated in CRC [70]. Some evidence for a beneficial effect comes from a 2005 meta-analysis, which demonstrated a decrease in CRC in those using 5-ASA [71]. There appears to be a dose-response relationship for chemoprevention, with a greater benefit being shown when subjects used $1.2 \mathrm{~g}$ per day compared to those using less, though lower doses still exhibited a protective effect $[61,72]$. A meta-analysis of the data revealed inconsistent results though, largely dependent on the referral base of each study [73]. 5-ASA is a treatment that is recommended in some cases of UC, while expert opinion cautions against its use in $\mathrm{CD}[74,75]$.

Ursodoxycholic acid was first used in UC patients, to treat effects of contaminant primary sclerosing cholangitis, and a relationship with decreased CRC was noted [76]. Follow-up studies have demonstrated mixed results [77-79], with some studies even noting an increase CRC risk in when high-doses of ursodoxycholic acid were employed [80].

Immunomodulators are another popular class of drug in IBD [81]. This class of medications mainly refers to azathioprine and methotrexate. Both of these drugs are considered anti-inflammatory. Methotrexate and its breakdown products act to inhibit enzymes in the metabolic pathway for creation of folic acid. At high doses, methotrexate is responsible for inhibition of DNA, RNA and protein synthesis, but at lower doses it likely decreases other folate dependent enzymes that prompt and propagate inflammation. Azathioprine is a purine analogue. It inhibits DNA synthesis, by acting as a prodrug for mercaptopurine. It has a strong effect on immune cells, and can leave the patient at risk of bone marrow suppression [81]. Recent evidence, in the form of a large prospective epidemiologic study suggested that thiopurines are protective against CRC in IBD [82]. Despite other recent literature has supporting this decrease $[83,84]$, the risk profile associated with these drugs leave them an unlikely candidate to be recommended as therapy as a preventative method alone.
The newest drug classes used in IBD have been termed 'biologics'. These are anti-tumor necrosis factor (TNF) drugs, the two most prominent examples being infliximab and adalimumab [81]. Infliximab is a chimeric monoclonal artifical antibody developed in mice and engineered for humans. Adalimumab is a human monoclonal antibody. Both of these agents have been shown to be very potent in inducing and maintaining remission of $\mathrm{CD}$, but due to their relatively recent discovery, long term efficacy and side effects have not been well described [81]. They can induce and maintain IBD remission, and that reduction in long standing inflammation may decrease CRC risk. A direct effect has been suggested, where mice with a pre-disposition to colonic neoplasia are delivered an TNF- $\alpha$ antagonist, tumor number and size decreased [85].

Initial studies on folate supplementation in the IBD population demonstrated a greater than $60 \%$ decrease in the incidence of colonic neoplasia [86], though this study failed to achieve statistical significance. Vitamin D deficiency has been associated with an increased risk of CRC [87], and supplementation should be considered in IBD.

Statins may promote apoptosis of colon cancer cells [88], and a subset analysis of a population-based study demonstrated a 94\% CRC risk reduction in IBD patients taking statins [89].

Another tool that clinicians have is screening colonoscopy, with the caveat that screening has not been shown to improve survival in patients with extensive colitis [90]. The goal of most surveillance programs is early detection and mortality reduction from IBD-associated CRC. Recent advance in chromoendoscopy have shown improved dysplasia detection rates, and should prove to be an effective tool against IBDassociated CRC [91-95]. Guidelines agree that dysplasia screening should take place through colonoscopy beginning 8 to 10 years after diagnosis (excluding isolated proctitis who should be screened as the general population) [96-98]. The picture becomes less clear following the initial colonoscopy as patients must be risk stratified at this point. Low-risk patients are those with quiescent disease or left-sided colitis alone, and should be screened every five years. Intermediate-risk includes those with mild inflammation, post-inflammatory polyps or a family history of CRC in a first degree relative over [50]. These patients require screening every three years. The high-risk group, who should be screened yearly, includes those with moderate or severe disease activity, primary scleroscing cholangitis, colonic stricture in the previous 5 years, previous dysplasia in the last 5 years and a family history of CRC in a first degree relative under $[50,98]$.

\section{Conclusion}

The relationship between IBD and the inflammation that it causes, the CRC that arise in this environment is a complicated one. Currently, the clinician can use the available tools to first, control inflammation, and second, actively screen and risk stratify those with IBD, in an attempt to optimize the care of this condition. The important question of the interaction between risk factors at the genetic and molecular level will continue to be explored in the hope that a greater understanding of IBD-associated CRC will lead to more targeted preventative therapies, and better management of this disease process.

\section{References}

1. Cosnes J, Gower-Rousseau C, Seksik P, Cortot A (2011) Epidemiology and natural history of inflammatory bowel diseases. Gastroenterology 140: 17851794.

2. Benchimol El, Guttmann A, Griffiths AM, Rabeneck L, Mack DR,et al. (2009) Increasing incidence of paediatric inflammatory bowel disease in Ontario, 
Canada: evidence from health administrative data. Gut 58: 1490-1497.

3. Kappelman MD, Rifas-Shiman SL, Kleinman K, Ollendorf D, Bousvaros A, et al. (2007) The prevalence and geographic distribution of Crohn's disease and ulcerative colitis in the United States. Clin Gastroenterol Hepatol 5: 1424-1429.

4. Peng Yu A, Cabanilla LA, Qiong Wu E, Mulani PM, Chao J (2007) The costs of Crohn's disease in the United States and other Western countries: a systematic review Curr Med Res Opin 24: 319-328.

5. CROHN BB, Rosenberg H (1925) The sigmoidoscopic picture of chronic ulcerative colitis (non-specific). The American J Med Sci 170: 220-227.

6. Dixon CF (1938) Regional enteritis. Annal surg 108: 857.

7. Rubin DC, Shaker A, Levin MS (2012) Chronic intestinal inflammation: inflammatory bowel disease and colitis-associated colon cancer. Front Immunol 3.

8. Parkin D (2005) Cancer IAfRo, Organization WH. Cancer incidence in five continents: IARC Press.

9. Wiseman M (2008) The second World Cancer Research Fund/American Institute for Cancer Research expert report. Food, nutrition, physical activity, and the prevention of cancer: a global perspective. Proc Nutr Soc 67: 253-256.

10. Sebastian S, Hernández V, Myrelid P, Kariv R, Tsianos E, et al. (2014) Colorectal cancer in inflammatory bowel disease: results of the 3rd ECCO pathogenesis scientific workshop (I). J Crohn's Colitis 8: 5-18.

11. Lakatos PL, Lakatos $L$ (2012) Challenges in calculating the risk for colorectal cancer in patients with ulcerative colitis. Clinical Gastroenterolog Hepatolog 10: 1179.

12. Katsanos K, Vermeire S, Christodoulou D, Riis L, Wolters F, et al. (2006) Dysplasia and cancer in inflammatory bowel disease 10 years after diagnosis: results of a population-based European collaborative follow-up study. Digestion 75: 113-121.

13. Gong W, Lv N, Wang B, Chen Y, Huang Y, et al. (2012) Risk of ulcerative colitisassociated colorectal cancer in China: a multi-center retrospective study. Dig Dis Sci 57: 503-507.

14. Kim BJ, Yang SK, Kim JS, Jeen YT, Choi H, et al. (2009) Trends of ulcerative colitis $\square$ associated colorectal cancer in Korea: A KASID study. Journal of gastroenterology and hepatology 24: 667-671.

15. Hata K, Watanabe T, Kazama S, Suzuki K, Shinozaki M, et al. (2003) Earlier surveillance colonoscopy programme improves survival in patients with ulcerative colitis associated colorectal cancer: results of a 23-year surveillance programme in the Japanese population. Br J Cancer 89: 1232-1236.

16. Eaden J, Abrams K, Mayberry J (2001) The risk of colorectal cancer in ulcerative colitis: a meta-analysis. Gut 48: 526-535.

17. Jess T, Simonsen J, Jørgensen KT, Pedersen BV, Nielsen NM, et al. (2012) Decreasing risk of colorectal cancer in patients with inflammatory bowe disease over 30 years. Gastroenterology 143: 375-381.

18. Castańo-Milla C, Chaparro M, Gisbert JP (2012) Sa1237 Has the Risk of Developing Colorectal Cancer in Patients With Ulcerative Colitis Been Overstated? a Meta-Analysis. Gastroenterology 142: S-251.

19. Ekbom A, Adami H, Helmick C, Adami HO (1990) Increased risk of large-bowe cancer in Crohn's disease with colonic involvement. Lancet 336: 357-359.

20. Friedman S, Rubin PH, Bodian C, Harpaz N, Present DH (2008) Screening and surveillance colonoscopy in chronic Crohn's colitis: results of a surveillance program spanning 25 years. Clin Gastroenterol Hepatol 6: 993-998.

21. Basseri RJ, Basseri B, Vassilaki ME, Melmed GY, Ippoliti A, et al. (2012) Colorectal cancer screening and surveillance in Crohn's colitis. Journal of Crohn's and Colitis 6: 824-829.

22. Canavan C, Abrams K, Mayberry J (2006) Meta $\square$ analysis: colorectal and small bowel cancer risk in patients with Crohn's disease. Aliment Pharmacol Ther 23: $1097-1104$

23. von Roon AC, Reese G, Teare J, et al. (2007) The risk of cancer in patients with Crohn's disease. Diseases Dis Colon Rectum 50: 839-855.

24. Laukoetter MG, Mennigen R, Hannig CM, Osada N, Rijcken E, et al. (2011) Intestinal cancer risk in Crohn's disease: a meta-analysis. J Gastrointest Surg 15: $576-583$

25. 25. Manninen $P$, Karvonen A-L, Huhtala H, Aitola P, Hyöty M, et al. (2013)
The risk of colorectal cancer in patients with inflammatory bowel diseases in Finland: A follow-up of 20 years. J Crohns Colitis 7: e551-e557.

26. Kappelman MD, Farkas DK, Long MD, Erichsen R, Sandler RS, et al. (2014) Risk of cancer in patients with inflammatory bowel diseases: a nationwide population-based cohort study with 30 years of follow-up evaluation. Clin Gastroenterol Hepatol 12: 265-273.

27. Fleming M, Ravula S, Tatishchev SF, Wang HL (2012) Colorectal carcinoma: pathologic aspects. Journal of gastrointestinal oncology 3: 153

28. Vogelstein B, Kinzler KW (1993) The multistep nature of cancer. Trends in Genet 9: 138-141.

29. Markowitz SD, Bertagnolli MM (2009) Molecular basis of colorectal cancer. New England J Med 361: 2449-2460

30. van Heel DA, Fisher SA, Kirby A, Daly MJ, Rioux JD, et al. (2004) Inflammatory bowel disease susceptibility loci defined by genome scan meta-analysis of 1952 affected relative pairs. Hum Mol Genet 13: 763-770.

31. Salcedo R, Worschech A, Cardone M, Jones Y, Gyulai Z, et al. (2010) MyD88mediated signaling prevents development of adenocarcinomas of the colon: role of interleukin 18. J Exp Med 207: 1625-1636.

32. Rakoff-Nahoum S, Medzhitov R (2007) Regulation of spontaneous intestina tumorigenesis through the adaptor protein MyD88. Science 317: 124-127.

33. Fukata M, Abreu MT (2008) Role of Toll-like receptors in gastrointestina malignancies. Oncogene 27: 234-243.

34. Reimund J-M, Wittersheim C, Dumont S, Muller CD, Baumann R, et al. (1996) Mucosal inflammatory cytokine production by intestinal biopsies in patients with ulcerative colitis and Crohn's disease. J Clin Immunol 16: 144-150.

35. Popivanova BK, Kostadinova FI, Furuichi K, Shamekh MM, Kondo T, et al (2009) Blockade of a chemokine, CCL2, reduces chronic colitis-associated carcinogenesis in mice. Cancer Res 69: 7884-7892.

36. Grivennikov S, Karin M (2008) Autocrine IL-6 signaling: a key event in tumorigenesis? Cancer cell 13: 7-9.

37. Spolski R, Leonard WJ (2008) Interleukin-21: Basic Biology and Implications for Cancer and Autoimmunity. Annu Rev Immunol 26: 57-79.

38. Jauch D, Martin M, Schiechl G, Kesselring R, Schlitt HJ, et al. (2011) Interleukin 21 controls tumour growth and tumour immunosurveillance in colitis-associated tumorigenesis in mice. Gut 60: 1678-1686.

39. Grivennikov SI, Greten FR, Karin M. (2010) Immunity, inflammation, and cancer. Cell 140: 883-899.

40. Arkan MC, Greten FR. (2011) IKK-and NF-KB-mediated functions in carcinogenesis. Curr Top Microbiol Immunol 349: 159-69.

41. Greten FR, Eckmann L, Greten TF, et al. (2004) IKK $\beta$ links inflammation and tumorigenesis in a mouse model of colitis-associated cancer. Cell 118: 285296.

42. Li N, Grivennikov SI, Karin M (2011) The unholy trinity: inflammation, cytokines, and STAT3 shape the cancer microenvironment. Cancer cell 19: 429-431.

43. Grivennikov S, Karin E, Terzic J, Mucida D, Yu GY, et al. (2009) IL-6 and Stat3 are required for survival of intestinal epithelial cells and development of colitisassociated cancer. Cancer cell 15: 103-113.

44. Li Y, de Haar C, Chen M, Deuring J, Gerrits MM, et al. (2010) Disease-related expression of the IL6/STAT3/SOCS3 signalling pathway in ulcerative colitis and ulcerative colitis-related carcinogenesis. Gut 59: 227-235.

45. Mai V, Draganov PV (2009) Recent advances and remaining gaps in ou knowledge of associations between gut microbiota and human health. World J Gastroenterol 15: 81-85.

46. Morgan XC, Tickle TL, Sokol H, Gevers D, Devaney KL, et al. (2012 Dysfunction of the intestinal microbiome in inflammatory bowel disease and treatment. Genome Biol 13: R79.

47. Vanderploeg R, Panaccione R, Ghosh S, Rioux K (2010) Influences of intestinal bacteria in human inflammatory bowel disease. Infect Dis Clin North Am 24 977-993.

48. Li Y, Kundu P, Seow SW, de Matos CT, Aronsson L, et al. (2012) Gut microbiota accelerate tumor growth via c-jun and STAT3 phosphorylation in APCMin/+ mice. Carcinogenesis 33: 1231-1238. 
49. Dove WF, Clipson L, Gould KA, Luongo C, Marshall DJ, et al. (1997) Intestinal neoplasia in the ApcMin mouse: independence from the microbial and natural killer (beige locus) status. Cancer Res 57: 812-814

50. Chichlowski M, Sharp JM, Vanderford DA, Myles MH, Hale LP (2008) Helicobacter typhlonius and Helicobacter rodentium differentially affect the severity of colon inflammation and inflammation-associated neoplasia in IL10 deficient mice. Comp Med 58: 534-541.

51. Arthur JC, Perez-Chanona E, Mühlbauer M, Tomkovich S, Uronis JM, et al. (2012) Intestinal inflammation targets cancer-inducing activity of the microbiota. Science 338: 120-123.

52. Wu S, Rhee K-J, Albesiano E, Rabizadeh S, Wu X, et al. (2009) A human colonic commensal promotes colon tumorigenesis via activation of $\mathrm{T}$ helper type $17 \mathrm{~T}$ cell responses. Nat Med 15: 1016-1022.

53. Rabizadeh S, Rhee KJ, Wu S, Huso D, Gan CM, et al. (2007) Enterotoxigenic Bacteroides fragilis: a potential instigator of colitis. Inflamm Bowel Dis 13: 14751483.

54. Rutter MD, Saunders BP, Wilkinson KH, Rumbles S, Schofield G, et al. (2006) Thirty-year analysis of a colonoscopic surveillance program for neoplasia in ulcerative colitis. Gastroenterology 130: 1030-1038.

55. Söderlund S, Brandt L, Lapidus A, Karlén P, Broström O, et al. (2009) Decreasing time-trends of colorectal cancer in a large cohort of patients with inflammatory bowel disease. Gastroenterology 136: 1561-1567.

56. Ananthakrishnan AN, Cheng SC, Cai T, Cagan A, Gainer VS, et al. (2014) Serum inflammatory markers and risk of colorectal cancer in patients with inflammatory bowel diseases. Clin Gastroenterol Hepatol 12: 1342-1348.

57. Rutter M, Saunders B, Wilkinson K, Rumbles S, Schofield G, et al. (2004) Severity of inflammation is a risk factor for colorectal neoplasia in ulcerative colitis. Gastroenterology 126: 451-459.

58. Nieminen U, Jussila A, Nordling S, Mustonen H, Färkkilä MA (2014) Inflammation and disease duration have a cumulative effect on the risk of dysplasia and carcinoma in IBD: a case-control observational study based on registry data. Int J Cancer 134: 189-196.

59. Peng YC, Lin CL, Hsu WY, Chang CS, Yeh HZ, et al. (2014) The risk of colorectal cancer is related to frequent hospitalization of IBD in an Asian population: results from a nationwide study. QJM 2014: hcu225.

60. Jess T, Loftus EV Jr, Velayos FS, Winther KV, Tremaine WJ, et al. (2007) Risk factors for colorectal neoplasia in inflammatory bowel disease: a nested case-control study from Copenhagen County, Denmark and Olmsted County, Minnesota. Am J Gastroenterol 102: 829-836.

61. Eaden J, Abrams K, Ekbom A, Jackson E, Mayberry J (2000) Colorectal cance prevention in ulcerative colitis: a case-control study. Aliment Pharmacol Ther 14: $145-154$

62. Greenstein AJ, Sachar DB, Smith H, Andrews HA, Allan RN (1981)A comparison of cancer risk in Crohn's disease and ulcerative colitis. Cancer 48: 2742-2745.

63. Karvellas CJ, Fedorak RN, Hanson J, Wong CK (2007) Increased risk of colorectal cancer in ulcerative colitis patients diagnosed after 40 years of age. Can J Gastroenterol 21: 443-446.

64. Söderlund S, Granath F, Broström O, Karlén P, Löfberg R, et al. (2010) Inflammatory bowel disease confers a lower risk of colorectal cancer to females than to males. Gastroenterology 138: 1697-1703.

65. Lakatos L, Mester G, Erdelyi Z, David G, Pandur T, et al. (2006) Risk factors for ulcerative colitis-associated colorectal cancer in a Hungarian cohort of patients with ulcerative colitis: Results of a population-based study. Inf Bowel Dis 12 : 205-211.

66. Soetikno RM, Lin OS, Heidenreich PA, Young HS, Blackstone MO (2002) Increased risk of colorectal neoplasia in patients with primary sclerosing cholangitis and ulcerative colitis: a meta-analysis. Gastrointest Endosc 56: 4854.

67. Hanouneh IA, Macaron C, Lopez R, Zein NN, Lashner BA (2012) Risk of colonic neoplasia after liver transplantation for primary sclerosing cholangitis. Inflamm Bowel Dis 18: 269-274.

68. Vera A, Gunson BK, Ussatoff V, Nightingale P, Candinas D, et al. (2003) Colorectal cancer in patients with inflammatory bowel disease after liver transplantation for primary sclerosing cholangitis. Transplantation 75: 1983-1988.
69. Askling J, Dickman PW, Ekbom A, Broström O, Lapidus A, et al. (2001) Family history as a risk factor for colorectal cancer in inflammatory bowel disease. Gastroenterology 120: 1356-1362.

70. Lyakhovich A, Gasche C. (2010) Systematic review: molecular chemoprevention of colorectal malignancy by mesalazine. Aliment Pharmacol Ther 31: 202-209.

71. Velayos FS, Terdiman JP, Walsh JM. (2005) Effect of 5-aminosalicylate use on colorectal cancer and dysplasia risk: a systematic review and metaanalysis of observational studies. Am J Gastroenterol 100: 1345-1353.

72. van Staa TP, Card T, Logan R, Leufkens HG (2005) 5-Aminosalicylate use and colorectal cancer risk in inflammatory bowel disease: a large epidemiological study. Gut 54: 1573-1578.

73. Nguyen GC, Gulamhusein A, Bernstein CN (2012) 5-aminosalicylic acid is not protective against colorectal cancer in inflammatory bowel disease: a metaanalysis of non-referral populations. Am J Gastroenterol 107: 1298-1304.

74. Lichtenstein GR, Hanauer SB, Sandborn WJ (2009) Management of Crohn's disease in adults. Am J Gastroenterol 104: 465-483.

75. Travis S, Stange E, Lémann M, Oresland T, Chowers Y, et al. (2006) European evidence based consensus on the diagnosis and management of Crohn's disease: current management. Gut 55: i16-i35.

76. Tung BY, Emond MJ, Haggitt RC, Bronner MP, Kimmey MB, et al. (2001) Ursodiol use is associated with lower prevalence of colonic neoplasia in patients with ulcerative colitis and primary sclerosing cholangitis. Ann Intern Med 134: 89-95.

77. Pardi DS, Loftus EV, Kremers WK, Keach J, Lindor KD (2003) Ursodeoxycholic acid as a chemopreventive agent in patients with ulcerative colitis and primary sclerosing cholangitis. Gastroenterology 124: 889-893.

78. Wolf J, Rybicki L, Lashner B (2005) The impact of ursodeoxycholic acid on cancer, dysplasia and mortality in ulcerative colitis patients with primary sclerosing cholangitis. Aliment Pharmacol Ther 22: 783-788.

79. Ashraf I, Choudhary A, Arif M, Matteson ML, Hammad HT, et al. (2012) Ursodeoxycholic acid in patients with ulcerative colitis and primary sclerosing cholangitis for prevention of colon cancer: a meta-analysis. Ind J Gastroenterol 31: $69-74$

80. Eaton JE, Silveira MG, Pardi DS, Sinakos E, Kowdley KV, et al. (2011) Highdose ursodeoxycholic acid is associated with the development of colorectal neoplasia in patients with ulcerative colitis and primary sclerosing cholangitis. Am J Gastroenterol 106: 1638-1645.

81. Colombel JF, Sandborn WJ, Reinisch W, Mantzaris GJ, Kornbluth A, et al (2010) Infliximab, azathioprine, or combination therapy for Crohn's disease. New England Journal of Medicine 362: 1383-1395

82. Beaugerie L, Svrcek M, Seksik P, Bouvier AM, Simon T, et al. (2013) Risk of colorectal high-grade dysplasia and cancer in a prospective observational cohort of patients with inflammatory bowel disease. Gastroenterology 145 166-175.

83. Rubin DT, Huo D, Kinnucan JA, Sedrak MS, McCullom NE, et al. (2013) Inflammation is an independent risk factor for colonic neoplasia in patients with ulcerative colitis: a case-control study. Clin Gastroenterol Hepatol.11: 16011608

84. Gong J, Zhu L, Guo Z, Li Y, Zhu W, et al. (2013) Use of thiopurines and risk of colorectal neoplasia in patients with inflammatory bowel diseases: a metaanalysis. Plos one 8: e81487.

85. Popivanova BK, Kitamura K, Wu Y, Kondo T, Kagaya T, et al. (2008) Blocking TNF- $\alpha$ in mice reduces colorectal carcinogenesis associated with chronic colitis. J Clin Invest 118: 560

86. Lashner BA, Provencher KS, Seidner DL, Knesebeck A, Brzezinski A (1997) The effect of folic acid supplementation on the risk for cancer or dysplasia in ulcerative colitis. Gastroenterology 112: 29-32.

87. Ananthakrishnan AN, Cheng SC, Cai T, Cagan A, Gainer VS, et al. (2014) Association between reduced plasma 25-hydroxy vitamin $D$ and increased risk of cancer in patients with inflammatory bowel diseases. Clin Gastroenterology and Hepatol 12: 821-827.

88. Cho SJ, Kim JS, Kim JM, et al. (2008) Simvastatin induces apoptosis in human colon cancer cells and in tumor xenografts, and attenuates colitis-associated colon cancer in mice. Intl J Cancer 123: 951-957. 
Citation: Laffin M, Karmali S (2015) Colorectal Adenocarcinoma and Inflammatory Bowel Disease: An Update and Review. Surgery Curr Res 5: 249. doi:10.4172/2161-1076.1000249

Page 6 of 6

89. Bonovas S, Filioussi K, Flordellis CS, Sitaras NM (2007) Statins and the risk of colorectal cancer: a meta-analysis of 18 studies involving more than 1.5 million patients. J Clin Oncol 25: 3462-3468.

90. Collins PD, Mpofu C, Watson AJ (2006) Strategies for detecting colon cance and/or dysplasia in patients with inflammatory bowel disease. Cochrane Database Syst Rev.

91. Hurlstone D, Sanders D, Lobo A, McAlindon ME, Cross SS (2005) Indigo carmine-assisted high-magnification chromoscopic colonoscopy for the detection and characterisation of intraepithelial neoplasia in ulcerative colitis: a prospective evaluation. Endoscopy 37: 1186-1192.

92. Kiesslich R, Fritsch J, Holtmann M, Koehler HH, Stolte M, et al. (2003) Methylene blue-aided chromoendoscopy for the detection of intraepithelial neoplasia and colon cancer in ulcerative colitis. Gastroenterology 124: 880-888.

93. Kiesslich R, Goetz M, Lammersdorf K, Schneider C, Burg J, et al. (2007) Chromoscopy-guided endomicroscopy increases the diagnostic yield of intraepithelial neoplasia in ulcerative colitis. Gastroenterology 132: 874-882.

94. Marion JF, Waye JD, Present DH, I srael Y, Bodian C, et al. (2008) Chromoendoscopy-targeted biopsies are superior to standard colonoscopic surveillance for detecting dysplasia in inflammatory bowel disease patients: a prospective endoscopic trial. Am J Gastroenterol 103: 2342-2349.

95. 95. Rutter M, Saunders B, Schofield G, Forbes A, Price AB, et al. (2004) Pancolonic indigo carmine dye spraying for the detection of dysplasia in ulcerative colitis. Gut 53: 256-260

96. 96. Cairns SR, Scholefield JH, Steele RJ, Dunlop MG, Thomas HJ, et al. (2010 Guidelines for colorectal cancer screening and surveillance in moderate and high risk groups (update from 2002). Gut 59: 666-689.

97. 97. Shergill AK, Farraye FA (2014) Toward a consensus on endoscopic surveillance of patients with colonic inflammatory bowel disease. Gastrointest Endosc Clin N Am 24: 469-481.

98. 98. NICE CfCPa (2011) Colonoscopic surveillance for prevention of colorectal cancer in people with ulcerative colitis, Crohn's disease or adenomas. 